\title{
Return on marketing investments in B2B customer relationships: A decision-making and optimization approach.
}

Citation for published version (APA):

Streukens, S., van Hoesel, C. P. M., \& de Ruyter, J. C. (2011). Return on marketing investments in B2B customer relationships: A decision-making and optimization approach. Industrial Marketing Management, 40(1), 149-161. https://doi.org/10.1016/j.indmarman.2010.06.002

Document status and date:

Published: 01/01/2011

DOI:

10.1016/j.indmarman.2010.06.002

Document Version:

Publisher's PDF, also known as Version of record

\section{Document license:}

Taverne

\section{Please check the document version of this publication:}

- A submitted manuscript is the version of the article upon submission and before peer-review. There can be important differences between the submitted version and the official published version of record.

People interested in the research are advised to contact the author for the final version of the publication, or visit the DOI to the publisher's website.

- The final author version and the galley proof are versions of the publication after peer review.

- The final published version features the final layout of the paper including the volume, issue and page numbers.

Link to publication

\footnotetext{
General rights rights.

- You may freely distribute the URL identifying the publication in the public portal. please follow below link for the End User Agreement:

www.umlib.nl/taverne-license

Take down policy

If you believe that this document breaches copyright please contact us at:

repository@maastrichtuniversity.nl

providing details and we will investigate your claim.
}

Copyright and moral rights for the publications made accessible in the public portal are retained by the authors and/or other copyright owners and it is a condition of accessing publications that users recognise and abide by the legal requirements associated with these

- Users may download and print one copy of any publication from the public portal for the purpose of private study or research.

- You may not further distribute the material or use it for any profit-making activity or commercial gain

If the publication is distributed under the terms of Article $25 \mathrm{fa}$ of the Dutch Copyright Act, indicated by the "Taverne" license above, 


\title{
Return on marketing investments in B2B customer relationships: A decision-making and optimization approach
}

\author{
Sandra Streukens ${ }^{\mathrm{a}, *}$, Stan van Hoesel ${ }^{\mathrm{b}, 1}$, Ko de Ruyter $^{\mathrm{c}, 2}$ \\ a Department of Marketing and Strategy, Hasselt University, Agoralaan-Building D, BE-3590 Diepenbeek, Belgium \\ b Department of Quantitative Economics, Maastricht University, PO Box 616, 6200 MD Maastricht, The Netherlands \\ c Department of Marketing and Supply Chain Management, Maastricht University, PO Box 616, 6200 MD Maastricht, The Netherlands
}

\section{A R T I C L E I N F O}

\section{Article history:}

Received 1 September 2008

Received in revised form 9 March 2009

Accepted 12 November 2009

Available online 29 June 2010

\section{Keywords:}

Return on marketing

Relationship marketing

Optimization

Marketing decision making

\begin{abstract}
A B S T R A C T
The basic notion of relationship marketing entails that firms should strive for mutually beneficial customer relationships. By combining relationship marketing theory and operations research methods, this paper aims to develop and demonstrate a managerial decision-making model that business market managers can use to optimize and evaluate marketing investments in both a customer-oriented and economically feasible manner. The intended contributions of our work are as follows. First, we add to the return on marketing literature by providing a first decision-making approach that explicitly assesses the optimization of marketing investments in terms of profitability, effort, and resource allocation. Second, we show how the risk of marketing investments can be assessed using sensitivity analysis. By means of an empirical study the versatility of our decision-making approach is demonstrated by assessing various critical decision making issues for business marketing managers in detail.
\end{abstract}

(c) 2010 Elsevier Inc. All rights reserved.

\section{Introduction}

Consistent with the basic tenet of relationship marketing that a company should strive for mutually beneficial customer relationship (LaPlaca, 2004) there is a strong need for managerial decision-making models that combine marketing theory with mathematical rigor (Metters \& Marucheck, 2007; Bretthauer, 2004; Boudreau, Hopp, McClain, \& Thomas, 2003).

Recent work in business marketing management underscores this premise of uniting soft customer perceptions and hard objective measures in a single decision-making tool. For instance, Gök (2009) demonstrates the necessity and value of including forward-looking customer evaluative judgments like satisfaction in marketing performance evaluation. Furthermore, Seggie, Cavusgil, and Phelan (2007) underscore the need for linking marketing initiatives to quantifiable financial outcomes. Nevertheless, models that combine marketing theory and financial performance measures to guide marketing investment decision making are scant in the literature. Therefore, the aim of our study is to develop and demonstrate a practical and versatile decision-making approach that assists business market managers in

\footnotetext{
* Corresponding author. Tel.: +32 11268628.

E-mail addresses: sandra.streukens@uhasselt.be (S. Streukens), s.vanhoesel@maastrichtuniversity.nl (S. van Hoesel), k.deruyter@maastrichtuniversity.nl (K. de Ruyter).

${ }^{1}$ Tel.: +31433883727.

2 Tel.: +31433883839.
}

evaluating and optimizing marketing investments in an economically justified, yet customer-oriented manner.

In line with the aforementioned need for decision-making models that combine marketing theory with mathematical rigor the two main building blocks of our approach include relationship marketing theory and operations research techniques. Anchoring the model in operations research principles permits decision makers to explicitly balance marketing revenues and costs. The use of relationship marketing theory to conceptualize different elements in the decision-making model warrants customer-oriented decision making. This study contributes to the literature in the following ways. First, compared to existing models, the present approach adds to the return on marketing literature by explicitly optimizing marketing investment profitability both in terms effort level as well as effort allocation. Second, we show how investment risk can be assessed by examining the robustness (i.e. sensitivity analysis) of the model's projected financial consequences.

The remainder of this paper is structured as follows. The following section focuses on the theoretical development of our decision-making approach, by first providing a general overview of our decision-making model and subsequently providing a detailed explanation of the various elements and links that the model encompasses. The paper then summarizes the empirical study conducted to calibrate the customer relationship part, or more precisely the marketing investment revenue component, of our approach. Building on the results of this empirical study, we show how our model can be used to tackle critical decisionmaking issues such as optimizing marketing investment profitability, optimizing marketing investment effort allocation and assessing marketing investment risk. In the final two section, we respectively discuss 
the various implications for business market managers and explain how our optimization approach can be extended to accommodate situations other than the one illustrated in this paper.

\section{Model development}

We start this section with a general overview of the main components of our decision-making model and their interrelationships. Subsequently, the different components are specified into detail.

\subsection{Overview of the decision-making approach}

The starting point of our decision-making approach adheres to the foundations of relationship marketing in that customer-firm relationships should be beneficial for both parties (see also LaPlaca, 2004). The idea of mutually beneficial customer-firm relationships is also reflected in the return on marketing approach (see also Rust, Zahorik, \& Keiningham, 1995) proposing that marketing investments should improve a firm's financial performance via improvements in customer evaluative judgments. Consequently, an effective decision-making model guiding marketing investments should thus carefully and explicitly balance changes in customers' perceptions stemming from marketing investments and the firm's financial consequences of these marketing investments.

In order to arrive at a decision-making approach to select marketing investments that contribute to the establishment of mutual beneficial relationships, the following two elements are of crucial importance. First, in line with Zhu, Sivakumar, and Parasuraman (2004) our decision-making framework should explicit take into account both the involved marketing investment revenues and costs, thereby enabling firms to conduct an economically justified analysis of marketing investments. Second, changes in customer evaluative judgments resulting from marketing investments should be explicitly connected to financial consequences. To this end, relationship marketing theory serves as a guide in modeling the marketing investment revenues in our approach.
Fig. 1 below graphically presents the main elements of our decisionmaking approach as well as their interrelationships.

The first link (i.e., Link 1 ) in Fig. 1 represents the positive relationship between the revenues stemming from marketing investments and the associated profitability of these investments. In line with the so-called expected value approach, which has been widely applied in finance and accounting and recent work in customer equity modeling (see Kumar \& George, 2007), our decision-making approach models the marketing investment revenues as the product of a customer's retention probability and his monetary value which is subsequently summed over the firm's customers. Pursuing an expected value approach to model marketing investment revenues offers several opportunities. First, the use of predictive response modeling to assess the probability that customers remain loyal over a given period enables the incorporation of key relationship marketing constructs into the calculation of marketing investment revenues and profitability. Second and synergistically, by integrating customer relationship perceptions in the marketing investment revenues/profitability calculation the development of truly customer-oriented marketing investments strategies can be guaranteed. In specifying the process underlying the generation of marketing investment revenues related to Link 1 in Fig. 1, we heavily draw upon relationship marketing theory (see also the rectangle denoted "relationship marketing theory" in Fig. 1).

The profitability consequences of marketing investment costs or effort are reflected by Links 2 and 3 in Fig. 1. Two separate paths are needed to adequately capture the dual impact that these costs have on profitability: (1) their indirect positive influence on profitability via the customer evaluative judgments they aim to improve (i.e. Link 2), and (2) their direct negative impact on investment profitability (i.e. Link 3). To model Links 2 and 3 we make use of decision calculus.

The remainder of this section explains the various elements presented in Fig. 1, captures them in mathematical equations, and finally integrates the elements in a mathematical framework that can be used to evaluate and optimize marketing investments.

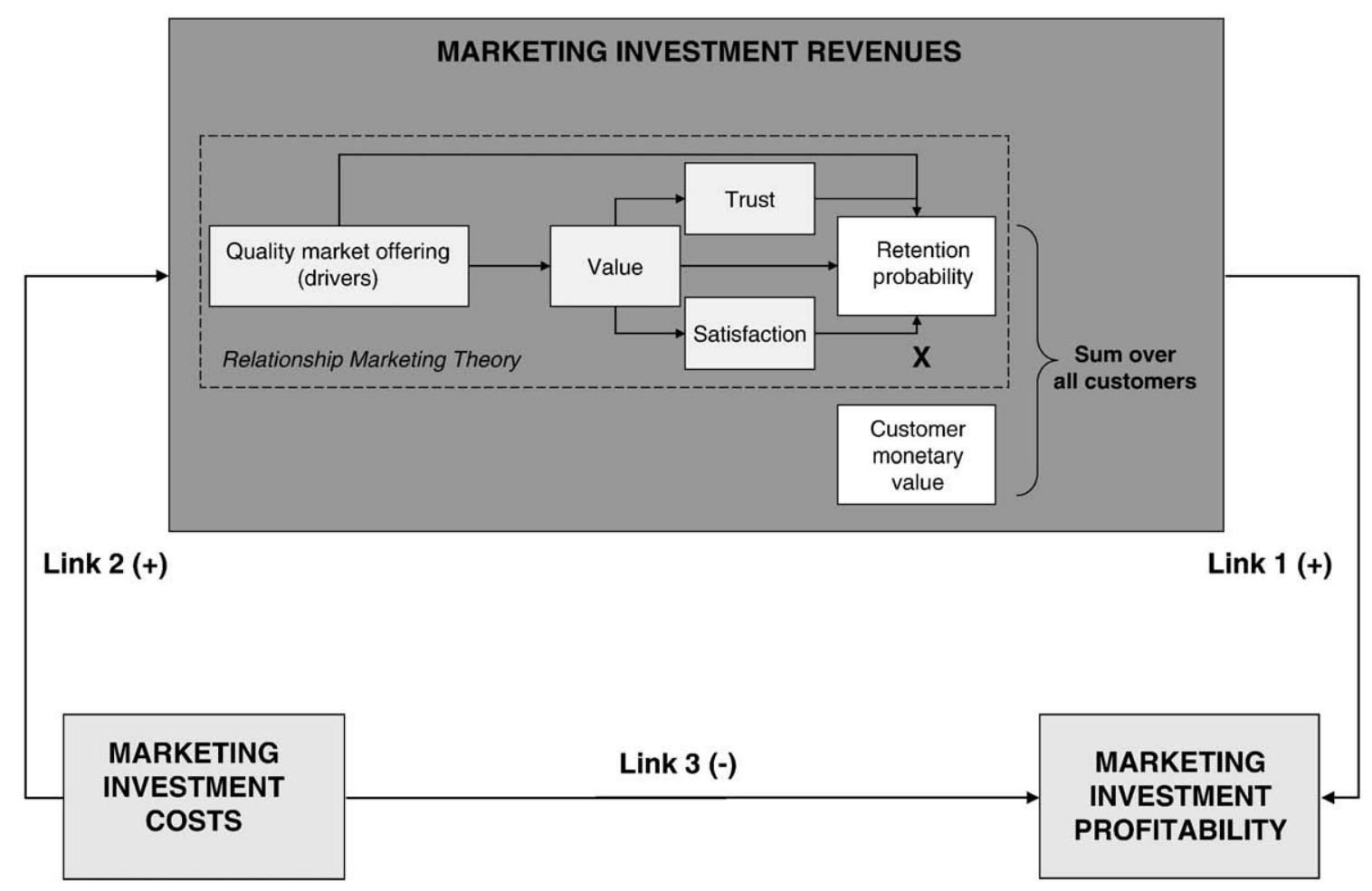

Fig. 1. Overview of the key elements of the optimization framework. 


\subsection{Modeling marketing investment revenues}

This paragraph focuses on modeling the marketing investment revenues function and the integration of this function in our decisionmaking model. First we explain the role of relationship marketing theory in modeling the marketing investment revenues function. Second, we show how the resulting revenues function can be incorporated in our mathematical decision-making model.

As outlined above and depicted in Fig. 1, the probability that a customer is retained over a certain time period by the company plays a crucial role in determining marketing investment revenues (and thus ultimately marketing investment profitability). Consequently, it is necessary to identify drivers of this customer retention probability in order to develop profitable marketing initiatives. To understand the customer's retention probability in business settings the beliefs $\rightarrow$ attitude behavioral intent model offers a valuable conceptual model (Lewin, 2009; Lam, Shankar, Erramilli, \& Murthy, 2004).

Building on the general structure of the beliefs attitude behavioral intent model the following constructs are used in modeling the marketing investment revenues function.

\subsection{Beliefs}

In explaining customer attitudes and behavior, perceived quality and perceived value are considered the two most important beliefs (Cronin, Brady, \& Hult, 2000). Perceived quality is the consumers' cognition-based appraisal of an offerings overall excellence or superiority (Zeithaml, 1988). Perceived value captures the customer's trade-off between sacrifices and returns involved in using a particular market offering (Cronin et al., 2000).

\subsection{Attitudes}

Two key attitudinal contructs in the formation of customer loyalty are satisfaction and trust (Selnes, 1998; Garbarino \& Johnson, 1999). Satisfaction is the customers' cumulative evaluation that is based on all experiences with the company's offering over time (Anderson, Fornell, \& Lehmann, 1994). Trust is the customer's confidence that the seller can be relied on to deliver according to their promises (Nijssen, Singh, Sirdeshmukh, \& Holzmueller, 2003).

\subsection{Behavioral intentions}

Finally, following common practice in customer research, we use behavioral intentions as a proxy for customer loyalty. Customer loyalty is a buyer's overall attachment to an offering, brand, or organization (Oliver, 1999). Moreover, similar to other return on marketing models, this study conceptualizes customer loyalty as the probability of securing the customers' monetary value over a specific time period (Rust, Lemon, \& Zeithaml, 2004). Table 1 summarizes findings of some major studies

Table 1

Literature overview relationship dynamics.

\begin{tabular}{|c|c|}
\hline Relationship & Literature in support of the hypothesized relationship \\
\hline QUAL $\rightarrow$ VALUE & $\begin{array}{l}\text { Cronin et al. (2000), Sweeney, Soutar, and Johnson (1999), Bolton, } \\
\text { and Drew (1991) }\end{array}$ \\
\hline $\mathrm{QUAL} \rightarrow \mathrm{SAT}$ & $\begin{array}{l}\text { Lewin (2009), Cronin et al. (2000), Bolton (1998), Anderson, } \\
\text { and Sullivan (1993) }\end{array}$ \\
\hline VALUE $\rightarrow$ SAT & Lewin (2009), Lam et al. (2004), Cronin et al. (2000) \\
\hline $\mathrm{SAT} \rightarrow \mathrm{TRUST}$ & Selnes (1998), Ganesan (1994) \\
\hline QUAL $\rightarrow$ TRUST & Singh, and Sirdeshmukh (2000), Gounaris (2005) \\
\hline VALUE $\rightarrow$ SAT & Lewin (2009), Lam et al. (2004) \\
\hline VALUE $\rightarrow$ TRUST & Gwinner, Gremler, and Bitner (1998) \\
\hline $\mathrm{SAT} \rightarrow$ LOY & Lewin (2009), Lam et al. (2004), Anderson, and Sullivan (1993) \\
\hline TRUST $\rightarrow$ LOY & $\begin{array}{l}\text { Keh, and Xie (2009) Garbarino, and Johnson (1999), Singh, and } \\
\text { Sirdeshmukh (2000) }\end{array}$ \\
\hline QUAL $\rightarrow$ LOY & Nijssen et al. (2003), Cronin et al. (2000) \\
\hline VALUE $\rightarrow$ LOY & Lam et al. (2004), Cronin et al. (2000) \\
\hline
\end{tabular}

regarding the relationships among the various belief, attitude, and intent constructs defined above.

In addition to understanding how customer evaluative judgments relate to marketing investment revenues, we need to integrate the set of relationships connecting customer beliefs, attitudes, and behavioral intent into our marketing investment decision-making approach. To achieve this we proceed as follows.

Maintaining with the notion of a chain of effects between beliefs, attitudes, and behavioral intentions, investments aimed at improving customer quality perceptions (i.e., beliefs) are assumed to eventually trigger an increase in customer retention probability. Or analogous to Rust et al. (2004) return on marketing terminology, customer quality perceptions are retention probability drivers. Without loss of generality, the remainder of this paper focuses on the financial consequences of marketing investments aimed at improving customer quality perceptions. These drivers (i.e., quality perceptions) are denoted as $y_{i}(i \in I)$.

Building on the nomological network connecting quality perceptions to customer retention, the impact of changes in the various drivers $y_{i}(i \in I)$ due to targeted marketing investments positively influences customer retention rates and thus eventually marketing investment revenues. The overall influence of changes in the various drivers on the customer's retention probability can be summarized by function $f_{y_{i}, l o y_{c}}$. As will be shown in section four of this paper, function $f_{y_{i}, l o y_{c}}$ can be determined directly from empirical analysis of the set of hypothesized relationships among the different customer constructs linking customer quality perceptions to customer retention.

To ultimately determine the marketing investment revenues, the customer retention probability is to be multiplied by the amount of customer monetary value $\left(C M V_{c}\right)$ that a customer is likely to generate over a specific time period and summed over all the relevant customers. Mathematically, this is expressed in Eqs. (1a) and (1b) below.

$$
R E V=\sum_{c=1}^{c}\left[\left(\operatorname{loy}_{c} C M V_{c}\right)-\left(\operatorname{loy}(0)_{c} C M V(0)_{c}\right)\right]
$$

Where

$\operatorname{loy}_{c}=\sum_{i \in I} f_{y_{i}, l o y_{c}} y_{i}$

In Eq. (1a) the term $l o y_{c}$ refers to the customer retention probability as a result of some particular marketing investment, whereas the term $\operatorname{loy}(0)_{c}$ is the status quo customer retention probability and refers to the customer retention probability before the implementation of the marketing initiative aimed at increasing customer retention. Furthermore, the terms $C M V(0)_{c}$ and $C M V_{c}$ refer to the customer monetary value before and after the marketing investment, respectively. Thus, Eq. (1a) implies that marketing investment revenues are the difference between the current customer revenues (associated with the current level of customer evaluative judgments) and the revenues that can be expected when marketing investments aimed at influencing customer evaluative judgments are made. In Eq. (1b) the term $f_{y_{i}}$ loy $y_{c}$ denotes the impact of the different drivers $y_{i}$ on the customer's retention probability over some time period as reflected by the nomological network of relationships connecting quality perceptions to customer retention probability (see also rectangle named "relationship marketing theory" in Fig. 1).

\subsection{Modeling marketing investment costs}

As reflected by Links 2 and 3 in Fig. 1, marketing investment costs or efforts have both a direct negative and an indirect positive effect on marketing investment profitability. The indirect positive effect stems from the fact that targeted marketing investments (denoted by eff $i$ ) influence customers' quality perceptions $\left(y_{i}\right)$, which through increased 
loyalty, yield marketing investment revenues (see also Link 2 in Fig. 1). Thus, the quantification of this particular positive relation between investment effort $\left(e f f_{i}\right)$ and the level of the drivers $\left(y_{i}\right)$ is crucial to the development of our decision-making model. The response curve proposed in Little (1970) ADBUDG function is used to estimate this relationship. The value of Little (1970) ADBUDG model is two-fold. First of all, ADBUDG offers a "simple, robust, easy to control, adaptive, as complete as possible, and easy to communicate with" (Little, 1970: 66) modeling approach. Second, as the parameters of the model are calibrated in consultation with managers, the ADBUDG model reflects Blattberg and Hoch (1990) notion that decision quality is best when both statistical and human input is combined. In general terms, the ADBUDG function is defined as shown in Eq. (2).

$y_{i}=a_{i}+\left(b_{i}-a_{i}\right) \frac{e f f_{i}^{c_{i}}}{d_{i}+e f f_{i}^{c_{i}}}$

Concerning Eq. (2), parameters $a_{i}$ and $b_{i}$ restrict driver $y_{i}$ to a meaningful range (i.e., $\left[a_{i}, b_{i}\right]$ ). More specifically, $a_{i}$ represents the level of driver $i$ (i.e., $y_{i}$ ) when no marketing investments are made for this variable (i.e., $e f f_{i}=0$ ); $b_{i}$ corresponds to the value of the driver when an infinite amount of resources would be invested in this driver (i.e. $e f f_{i} \rightarrow \infty$ ). Parameters $c_{i}$ and $d_{i}$ determine the shape of the relationship between $y_{i}$ and $e f f_{i}$. More specifically, parameter $c_{i}$ allows the response curve to be either concave or s-shaped, whereas parameter $d_{i}$ reflects the slope of the response curve.

Calibration of the ADBUDG function shown in Eq. (2) automatically provides an estimate of the total level of investment costs, which has a direct negative impact on the profitability of marketing investments (see also Link 3 in Fig. 1). The total level of marketing investment costs equals the amounts invested in the different drivers summed over all relevant drivers. Thus, as eff $f_{i}$ reflects the investment effort needed to influence a particular customer retention driver $y_{i}$, the total investment effort associated with a particular investment strategy aimed at improving a set of drivers can be defined as:

Total efforts $=\sum_{i \in I}\left(e f f_{i}-e f f(0)_{i}\right)$

In Eq. (3) the term $\operatorname{eff}(0)_{i}$ in the investment level needed to maintain the $y(0)_{i}$ level of the drivers (please note that this relationship is implied by Eq. (2)). Furthermore, the $y(0)_{i}$ levels of the drivers correspond with the $\operatorname{loy}(0)_{c}$ parameter in Eq. (1a). As indicated by Link 3 of our conceptual model in Fig. 1, the level of total invest effort directly reduces the profitability of marketing investments.

\subsection{Modeling and optimizing marketing investment profitability}

The profitability of marketing investments equals the difference between the revenues and costs associated with a particular marketing investment. Consequently, the profitability function, presented in Eq. (4), follows directly from the combination of the revenue and total investment effort function expressed in Eqs. (1a) and (3) respectively.

profits $=\left[\sum_{c=1}^{c}\left[\left(\log _{c} C M V_{c}\right)-\left(\operatorname{loy}(0)_{c} C M V(0)_{c}\right)\right]\right]-\left[\sum_{i \in I}\left[\operatorname{eff} f_{i}-e f f(0)_{i}\right]\right]$

Similar to the work of Rust et al. (1995, 2004) Eq. (4) yields sufficient information to make marketing investments financially accountable and to compare and evaluate them vis-à-vis alternative (marketing) investment opportunities. In addition to making marketing investments financially accountable, optimizing marketing investment profitability is an issue of great managerial interest (Zeithaml, 2000) which so far has received little attention in the existing literature.
In order to devise marketing investment strategies that maximize profitability, the expression presented in Eq. (4) serves as an objective function in an optimization problem. The core of this optimization problem is to maximize marketing investment profitability by finding optimal spending levels effi for the different drivers $y_{i}$. Or equivalently, the aim is to determine which spending levels eff $_{i}$ would yield optimal levels of customer perceptions regarding the different drivers $y_{i}$ as reflected by a maximum level of marketing investment profitability.

Building on the interrelationships among marketing investment profitability, revenues, and costs (see also Fig. 1), maximizing the profitability function is subject to the following constraints. The first constraint, presented below in Eq. (5a) models the impact of changes in the input variables $y_{i}$ on the retention probability as hypothesized by the set of relationships underlying the loyalty formation process (see also rectangle "Relationship Marketing Theory" in Fig. 1).

$\operatorname{loy}_{c}=\sum_{i \in I} f_{y_{i}, l_{y_{c}}} y_{i}$

The second constraint models the effect of investment effort eff $f_{i}$ on the level of the input variables $y_{i}$ following Little (1970) ADBUDG function. As a reminder, this constraint is modeled as follows (see also Eq. (2)).

$y_{i}=a_{i}\left(b_{i}-a_{i}\right) \frac{e f f_{i}^{c_{i}}}{d_{i}+e f f_{i}^{c_{i}}}$

Third, we impose a budget constraint implying that the total investment effort cannot exceed a pre-set budget $B$. This budget constraint is summarized in Eq. (5c).

$\sum_{i \in I}\left(e f f_{i}-e f f(0)_{i}\right) \leq B$

Finally, we impose a nonnegativity constraint for eff $f_{i}$ which is formally expressed in Eq. (5d).

$e f f_{i}-\operatorname{eff}(0)_{i} \geq 0$

Together the objective function and constraints described above yield the optimization framework presented in Exhibit 1.

Exhibit 1. Overview of the decision-making/optimization framework

\begin{tabular}{|c|c|c|c|c|}
\hline $\max$ & $\sum_{c=1}^{C}\left[\left(\log _{c} C M V_{c}\right)-(\operatorname{loy}(0)\right.$ & ]- & $\sum_{i \in I}\left[e f f_{i}-e f f(0)_{i}\right]$ & \\
\hline \multirow[t]{4}{*}{ s.t. } & $\operatorname{loy}_{c}$ & $=$ & $\sum_{i \in I}\left[f_{y_{i}, l_{y_{c}}} y_{i}\right]$ & $\forall_{i \in I}$ \\
\hline & $y_{i}$ & & $+\left(b_{i}-a_{i}\right) \frac{e f f}{d_{i}+}$ & $\forall_{i \in I}$ \\
\hline & $\sum_{i \in I}\left(e f f_{i}-e f f(0)_{i}\right)$ & $\leq$ & B & $\forall_{i \in I}$ \\
\hline & $e f f_{i}-e f f(0)_{i}$ & $\geq$ & 0 & $\forall_{i \in I}$ \\
\hline
\end{tabular}

In the following two sections the various parameters required to implement the decision-making or optimization model will be estimated and calibrated. The following section describes the empirical study conducted to understand and model the marketing investment revenues function consisting of the customer's retention probability and the customer monetary value (see also Eqs. (1a) and (1b)). The section after that uses the results of this empirical study to 
demonstrate the various possibilities our optimization framework in Exhibit 1 offers for marketing decision making.

\section{Analyzing customer retentions and customer monetary value}

\subsection{Sampling}

Survey data needed to estimate the different elements of the marketing investment revenues function (see also Fig. 1 and Eqs. (1a) and (1b)) were collected from business customers a particular business unit within a large international operating manufacturer of office equipment. This business unit sells the supplies (e.g. paper and toner) needed to operate the organization's office equipment (copiers and printers). Furthermore, the company aims to build long-term relationship with its customers based on service excellence. The population of this study consists of B2B customers for which it is economically infeasible to pursue a one-to-one marketing strategy. Overall, these customers make up approximately $37.6 \%$ of the total customer base.

In total, we obtained an effective response rate of $36.6 \%$ or 183 respondents. Examination of the sample profile led to the conclusion that our sample is representative of the underlying target population. Furthermore, all questionnaires were labeled with the customers' unique ID-code enabling us to link the customer's perceptual and (objective) sales data.

\subsection{Data}

All respondents that participated in our study received a questionnaire containing items on perceived quality, overall satisfaction, perceived value, trust, and behavioral intentions. Perceived quality was measured by means of 7 attributes that covered the most important product and service aspects from the customers' point of view (cf. Rust et al., 1995). Overall cumulative satisfaction was measured by means of a single item (Anderson et al., 1994). Perceived value (4 items) was assessed using a scale that was adapted from the measurement instruments developed by Dodds, Monroe, and Grewal (1991) and Cronin et al. (2000). Trust (5 items) was measured by means of the scale developed by Kumar, Scheer, and Steenkamp (1995). All above- mentioned constructs were measured on 11-point Likert scales. The customer's retention probability was assessed by measuring the current percentage spent at the company under study relative to the total amount of money spent at the particular product category (Rust et al., 2004). See Table 2 for an overview of the descriptive statistics of the customer constructs assessed for this study. Moreover, Table 5 accompanying the application of our decision-making model contains a short description of each quality item or driver.

Finally, data on customer sales over an 18 month period were obtained from the company's data base. To account for customer differences in purchase times, monthly sales were summed over a three month's time period.

\subsection{Estimation procedure customer retention probability}

To estimate the relationships connecting customer perceptions regarding the various drivers to the customer retention probability, we opted for PLS path modeling (SmartPLS2.0 M3) as our model contains both formative and reflective scales. To restrict the (predicted) retention probabilities to a feasible 0 - 1 range, a logit transformation was applied to all stated retention probabilities. To our best knowledge, no PLS path modeling software is available to accommodate the resulting non-linear logit curve. To overcome this problem we proceeded as follows. Based on the retention probability we determined each respondent's odds ratio. Subsequently, taking the natural logarithm of the odds ratio and specifying it as a formative indicator for the loyalty construct allowed us to estimate it as a linear function of its hypothesized antecedents.

To evaluate the statistical significance of the various parameter estimates bias-corrected bootstrap percentile confidence intervals based on 5000 bootstrap samples are constructed.

\subsection{Estimation procedure customer monetary value}

In line with Venkatesan and Kumar (2004) customer monetary value $\left(C M V_{c}\right)$ is modeled as a function of past behavior and customer characteristics such as customer size, customer type, and relationship length. The following issues warrant specific attention when analyzing panel data. First, to accommodate the problem of endogeneity due to

Table 2

Descriptive statistics and psychometric properties.

\begin{tabular}{|c|c|c|c|c|c|c|c|c|c|c|c|c|c|c|c|c|c|c|c|}
\hline & & 1 & 2 & 3 & 4 & 5 & 6 & 7 & 8 & 9 & 10 & 11 & 12 & 13 & 14 & 15 & 16 & 17 & 18 \\
\hline 1 & QUAL1 & 1 & & & & & & & & & & & & & & & & & \\
\hline 2 & QUAL2 & 0.56 & 1 & & & & & & & & & & & & & & & & \\
\hline 3 & QUAL3 & 0.34 & 0.36 & 1 & & & & & & & & & & & & & & & \\
\hline 4 & QUAL4 & 0.42 & 0.37 & 0.23 & 1 & & & & & & & & & & & & & & \\
\hline 5 & QUAL5 & 0.39 & 0.54 & 0.35 & 0.32 & 1 & & & & & & & & & & & & & \\
\hline 6 & QUAL6 & 0.33 & 0.39 & 0.32 & 0.34 & 0.41 & 1 & & & & & & & & & & & & \\
\hline 7 & QUAL7 & 0.43 & 0.37 & 0.23 & 0.26 & 0.39 & 0.43 & 1 & & & & & & & & & & & \\
\hline 8 & SAT & 0.48 & 0.55 & 0.31 & 0.33 & 0.57 & 0.48 & 0.45 & 1 & & & & & & & & & & \\
\hline 9 & VALUE1 & 0.23 & 0.23 & 0.13 & 0.14 & 0.14 & 0.20 & 0.17 & 0.30 & 1 & & & & & & & & & \\
\hline 10 & VALUE2 & 0.30 & 0.35 & 0.13 & 0.24 & 0.32 & 0.25 & 0.25 & 0.41 & 0.66 & & & & & & & & & \\
\hline 11 & VALUE3 & 0.27 & 0.26 & 0.16 & 0.29 & 0.24 & 0.18 & 0.25 & 0.36 & 0.59 & 0.55 & 1 & & & & & & & \\
\hline 12 & VALUE4 & 0.20 & 0.26 & 0.17 & 0.23 & 0.35 & 0.21 & 0.20 & 0.37 & 0.45 & 0.46 & 0.45 & 1 & & & & & & \\
\hline 13 & TRUST1 & 0.22 & 0.22 & 0.14 & 0.18 & 0.18 & 0.18 & 0.22 & 0.33 & 0.47 & 0.47 & 0.41 & 0.33 & 1 & & & & & \\
\hline 14 & TRUST2 & 0.15 & 0.23 & 0.22 & 0.12 & 0.15 & 0.11 & 0.14 & 0.36 & 0.32 & 0.33 & 0.36 & 0.20 & 0.56 & 1 & & & & \\
\hline 15 & TRUST3 & 0.17 & 0.29 & 0.05 & 0.15 & 0.23 & 0.14 & 0.16 & 0.35 & 0.40 & 0.41 & 0.39 & 0.29 & 0.59 & 0.57 & 1 & & & \\
\hline 16 & TRUST4 & 0.16 & 0.23 & 0.21 & 0.24 & 0.16 & 0.13 & 0.09 & 0.30 & 0.29 & 0.33 & 0.31 & 0.19 & 0.60 & 0.58 & 0.61 & 1 & & \\
\hline 17 & TRUST5 & 0.13 & 0.31 & 0.12 & 0.19 & 0.21 & 0.12 & 0.16 & 0.37 & 0.45 & 0.45 & 0.45 & 0.35 & 0.64 & 0.57 & 0.72 & 0.68 & 1 & \\
\hline \multirow[t]{10}{*}{18} & $\mathrm{P}(\mathrm{LOY})$ & 0.20 & 0.26 & 0.07 & 0.27 & 0.29 & 0.04 & 0.18 & 0.36 & 0.25 & 0.32 & 0.38 & 0.28 & 0.32 & 0.23 & 0.34 & 0.24 & 0.41 & \\
\hline & MEAN & 7.82 & 7.61 & 6.97 & 7.50 & 7.50 & 7.52 & 7.49 & 8.76 & 8.20 & 8.47 & 8.68 & 6.85 & 8.58 & 7.44 & 8.63 & 7.75 & 8.33 & 0.72 \\
\hline & S.D. & 0.64 & 0.71 & 0.91 & 0.97 & 0.70 & 0.88 & 0.80 & 0.68 & 1.95 & 2.30 & 2.07 & 3.30 & 2.28 & 2.48 & 2.13 & 2.39 & 2.22 & 0.23 \\
\hline & LOADING & 0.70 & 0.80 & 0.44 & 0.54 & 0.82 & 0.67 & 0.64 & n.a. & 0.74 & 0.87 & 0.83 & 0.72 & 0.83 & 0.77 & 0.85 & 0.82 & 0.89 & n.a. \\
\hline & LOWER BOUND & 0.56 & 0.69 & 0.22 & 0.32 & 0.70 & 0.53 & 0.48 & n.a. & 0.57 & 0.74 & 0.71 & 0.54 & 0.76 & 0.68 & 0.78 & 0.73 & 0.84 & n.a. \\
\hline & UPPER BOUND & 0.82 & 0.90 & 0.65 & 0.73 & 0.91 & 0.80 & 0.78 & n.a. & 0.86 & 0.86 & 0.92 & 0.96 & 0.88 & 0.83 & 0.89 & 0.87 & 0.92 & n.a. \\
\hline & 1st EIGENVALUE & n.a. & & & & & & & n.a. & 2.59 & & & & 3.46 & & & & & n.a. \\
\hline & 2nd EIGENVALUE & n.a. & & & & & & & n.a. & 0.62 & & & & 0.48 & & & & & n.a. \\
\hline & CRONBACH'S $\alpha$ & n.a. & & & & & & & n.a. & 0.78 & & & & 0.89 & & & & & n.a. \\
\hline & AVE & n.a. & & & & & & & n.a. & 0.63 & & & & 0.69 & & & & & n.a. \\
\hline
\end{tabular}


Table 3

Empirical results structural model.

\begin{tabular}{|c|c|c|c|c|}
\hline Relationship & $\begin{array}{l}\text { Unstandardized } \\
\text { coefficient }\end{array}$ & $\begin{array}{l}\text { Standardized } \\
\text { coefficient }\end{array}$ & $\begin{array}{l}\text { Bias corrected bootstrap } \\
\text { percentile confidence interval }\end{array}$ & $\begin{array}{l}\text { Adjusted } R^{2} \text { bootstrap percentile } \\
\text { confidence interval }\end{array}$ \\
\hline $\mathrm{QUAL} \rightarrow \mathrm{VAL}$ & 0.595 & 0.446 & {$[0.259 ; 0.534]$} & VAL: $R^{2}(\operatorname{adj})=0.199^{*}$ \\
\hline $\mathrm{QUAL} \rightarrow \mathrm{SAT}$ & 0.763 & 0.606 & {$[0.476 ; 0.702]$} & \\
\hline $\mathrm{VAL} \rightarrow \mathrm{SAT}$ & 0.181 & 0.192 & {$[0.069 ; 0.327]$} & SAT: [0.489;0.508] \\
\hline QUAL $\rightarrow$ TRUST & Not significant & Not significant & Not significant & \\
\hline $\mathrm{VAL} \rightarrow$ TRUST & 0.436 & 0.448 & {$[0.281 ; 0569]$} & \\
\hline $\mathrm{SAT} \rightarrow \mathrm{TRUST}$ & 0.208 & 0.202 & {$[0.089 ; 0.326]$} & TRUST:[0.309;0.325] \\
\hline $\mathrm{QUAL} \rightarrow \mathrm{P}($ LOY $)$ & Not significant & Not significant & Not significant & \\
\hline $\mathrm{VAL} \rightarrow \mathrm{P}(\mathrm{LOY})$ & 0.993 & 0.277 & {$[0.097 ; 0.435]$} & \\
\hline $\mathrm{SAT} \rightarrow \mathrm{P}(\mathrm{LOY})$ & 0.558 & 0.147 & {$[0.006 ; 0.300]$} & \\
\hline TRUST $\rightarrow \mathrm{P}($ LOY $)$ & 0.999 & 0.271 & {$[0.098 ; 0.326]$} & P(LOY): [0.288;0.323] \\
\hline
\end{tabular}

* As VAL is a function of just an endogenous construct it is not possible to construct a bootstrap percentile confidence interval for its $\mathrm{R}^{2}$ (adj) value.

the use of lagged dependent variables which are needed to assess the effect of past behavior, we used the first difference specification of customer monetary value $\left(\Delta C M V_{c, t}=C M V_{c, t}-C M V_{c, t-1}\right)$ as the dependent variable in our model and $C M V_{c, t-2}$ as an independent variable (Baltagi, 2008). Second, to examine whether a one-way or two-way error component random effects ${ }^{3}$ model is most appropriate, a series of Breusch-Pagan will to be conducted (Wooldridge, 2002). The dynamic regression model for the situation at hand is summarized in Eq. (6)

$$
\begin{aligned}
\Delta C M V_{c, t}= & +\gamma_{1} C M V_{c, t-2}+\gamma_{2} \text { QUAN }_{c, t-1}+\gamma_{3} \text { SIZE1 }_{c}+\gamma_{4} \text { SIZE2 }_{c} \\
& +\gamma_{5} \text { TYP }_{c}+\gamma_{6} \text { TYP2 }_{c}+\gamma_{7} R E L_{c}+\varepsilon_{i, t}
\end{aligned}
$$

In Eq. (6), $Q U A N_{c, t-1}$ refers to the quantity purchased in US dollars by the customer in period $t-1, \operatorname{SIZE} 1_{c}$ and $S I Z E 2_{c}$ are dummies reflecting the size of the customer expressed in past sales volume (entire population is split into four groups based on quartiles, only the lowest three quartiles were included in our sampling frame), TYPE $1_{c}$ and $\mathrm{TYPE}_{c}$ are dummies reflecting the product line(s) the customer uses. All four dummy variables can be considered time-invariant. The variable $R E L_{c}$ denotes the length of customer's relationship with company measured in days since the first purchase. The variables $\triangle C M V_{c, t}$ and $C M V_{c, t-2}$ are as defined above. To estimate the dynamic regression model expressed in Eq. (6) SAS v9.2's PROC PANEL is used.

\subsection{Empirical results customer retention probability}

First, the psychometric properties of the various scales used to tap customer evaluative judgments are evaluated. In assessing the performance of the scales used in this study it is important to distinguish between (multiple-item) reflective and formative scales (MacKenzie, Podsakoff, \& Jarvis, 2005). In this study, perceived value and trust are considered reflective scales, whereas perceived quality is considered a formative scale.

Concerning the reflective scales, unidimensionality is evidenced by the fact that the first eigenvalue matrix of the respective item correlation matrices exceeds one, whereas the other eigenvalues are less than one (Tenenhaus, Esposito Vinzi, Chatelin, \& Lauro, 2005). Furthermore, reliability was evidenced as for both reflective scales the internal consistency statistic passed the 0.70 cut-off value. Support for the reflective scales' within-method convergent validity is provided by the high average variance extracted levels and the magnitude and significance of the indicator loadings.

Regarding formative scales, the most relevant type of validity is content validity (Diamantopoulos \& Winklhofer, 2001). The fact that we designed the scale assessing perceived quality scale to encompass

\footnotetext{
${ }^{3}$ A fixed effects panel data model was not feasible as all regressors except the lagged dependent variable are time constant.
}

all relevant business processes together with the significant loadings provides substantial evidence for the content validity of this formative scale.

Finally, for all scales used in this study discriminant validity was evidenced as all between-construct correlation coefficients significantly differ from an absolute value of 1 . See Table 2 for the relevant figures regarding the evaluation of the scales' psychometric properties.

Turning to the empirical results for the hypothesized structural relationships underlying the revenue generating process, which are presented below in Table 3 , the bootstrapped $\bar{R}^{2}$ confidence intervals indicate that the theoretical model has a good fit to the data. Furthermore, as indicated by the statistical significance for the majority of the regression coefficients it can be concluded that also in B2B settings managing customer attitudes and perceptions is vital in creating customer loyalty. Thus, as evidenced by the chain of effects connecting customer beliefs and attitudes to customer behavior, directing investment efforts aimed at improving customer beliefs such as perceived quality offer an important opportunity to make customers more loyal. Put differently, marketing investments aimed at improving customer evaluative judgments are an effective way to enhance revenues.

Although these empirical results provide useful insights on how to manage customer loyalty among business customers, they do not provide a resolution for important management issues such as the optimal amount and optimal allocation of investment efforts needed to improve customer evaluative judgments in an economically justified way. This underscores the need for a formal decision-making approach to evaluate and manage marketing investments even further.

\subsection{Empirical results customer monetary value}

A comparison of the results for the Breusch-Pagan test for both a one-way and two-way error component random effects model shows that a one-way error component random effects model is appropriate for the situation at hand $\left(\Delta \chi^{2}(1)=1.00\right)$. Furthermore, as evidenced by the $R^{2}$ value of 0.54 our model shows a good fit to the data. The estimation results for the various parameters in our dynamic regression model are presented below in Table 4 .

Table 4

Empirical results dynamic regression analysis.

\begin{tabular}{llll}
\hline $\begin{array}{l}\text { Independent } \\
\text { variables }\end{array}$ & Explanation dummy variables & $\begin{array}{l}\text { Unstandardized } \\
\text { coefficient }\end{array}$ & $\begin{array}{l}t \text {-value } \\
(p \text {-value })\end{array}$ \\
\hline $\mathrm{CMV}_{c, t-1}$ & & 0.30 & $6.60(p<0.0001)$ \\
$\mathrm{QUANT}_{c, t-2}$ & 0.64 & $23.06(p<0.0001)$ \\
$S I Z E 1_{c}$ & Compares size quartiles 1 and 2 & 1652 & $3.00(p=0028)$ \\
$\mathrm{SIZE2}_{c}$ & Compares size quartiles 1 and 3 & 6929 & $9.13(\mathrm{p}<0.0001)$ \\
$\mathrm{TYPE}_{\mathrm{c}}$ & Compares user of product & n.s. & \\
& line B to those of product line A & \\
TYPE2 $_{\mathrm{c}}$ & Compares used of product lines A & n.s. & \\
\hline
\end{tabular}


The results in Table 4 demonstrate that past customer monetary value, past purchase quantity, and customer size are important indicators of future customer monetary value.

Building on these empirical results on the customer loyalty formation process and customer monetary value (i.e., key elements of the marketing investment revenues component of our model), section four focuses on how these empirical results can be used to put our marketing investment decision-making approach into practice.

\section{Application of the decision-making approach}

This section demonstrates how our decision-making approach presented in Exhibit 1 can assist business market managers in tackling the following vital marketing investment issues: (1) what is the optimal level of marketing investment effort to maximize profitability; (2) what is the projected return on investment for a specific investment initiative; (3) how should we optimally allocate the investment efforts over the drivers; and (4) how risky is the projected investment strategy.

Before we can assess these issues, we first need to calibrate the functions pertaining to marketing investment revenues (i.e. Link 1 in Fig. 1) as well as the indirect positive and direct negative effect of investment effort on investment profitability (i.e. respectively Links 2 and 3 in Fig. 1). Please note that additional detailed background information on the calibration of the model components can be found in the appendices to this paper.

\subsection{Calibrating the investment revenues function}

The impact of each driver $y_{i}$ on the customer's retention probability, and thus ultimately marketing investment revenues and profitability, as reflected by $f_{y_{i} l o y_{c}}$, can be calculated directly from the empirical data presented in Tables 2 and 3 in the following way. Given that the model describing the revenue generating process is non-recursive (acyclic), the total influence of each input variable $y_{i}$ on $l o y_{c}$ is summarized below in Eq. (7) and will be referred to as $\lambda_{y_{1}, l_{1}}$ in the remainder of this paper.

$f_{y_{i}, l o y_{c}}=\lambda_{y_{i}, l o y_{c}}=\sum_{P:\left(y_{i} \rightarrow \operatorname{loy}_{c}\right)}\left(\prod_{\left(y_{i}, l o y_{c}\right) \in P} w_{i j}\right)$

In Eq. (7) $w_{i j}$ are the different marginal effects of the relevant independent variables on the relevant dependent variables as hypothesized in our relationship marketing theory model (see also Fig. 1). In words, Eq. (7) states that the effect of a unit change in driver $y_{i}$ on the customer's retention probability $l o y_{c}$ can be computed by calculating the product of the coefficients $w_{i j}$ belonging to each of the separate relationships connecting $y_{i}$ and $l o y_{c}$, and subsequently summing these products over all relevant paths connecting $y_{i}$ and $l o y_{c}$.

The computation of the marginal effects $w_{i j}$ depends on the functional form of the equations describing the various links in the structural model connecting $y_{i}$ and $l o y_{c}$. For relationships characterized by a linear functional form $w_{i j}$ equals the relevant unstandardized regression coefficient. For the logit equation with $\operatorname{loy}_{c}$ as dependent variable, $w_{i j}$ is computed as $w_{i j} * \frac{e^{-\left(a+w_{1 j} x_{1}+w_{2 j} x_{2}+\ldots+w_{k j} x_{k}\right)}}{\left(1+e^{-\left(a++w_{1 j} x_{1}+w_{2 j} x_{2}+\ldots+w_{k j} x_{k}\right)}\right)^{2}}$ where the $w_{i j}$-parameters are the relevant unstandardized coefficients belonging to the $k$ independent variables. All needed unstandardized regression coefficients result from our empirical study (see also Tables 2 and 3). Following the idea expressed in Eq. (7), Table 5 summarizes the average influence of a one-unit change in $y_{i}$ on a customer retention probability $\operatorname{loy}_{c}$ for the situation at hand.

The dynamic regression results presented in Table 4 are used to predict the customer monetary value over the next time period (quarter). In combination, the customer retention probability as a function of drivers $y_{i}$ on the one hand and the estimates for each customer's monetary value on the other hand provide the necessary information to model the customer revenues function reflected by Eq. (1a).

\subsection{Calibrating the investment effort functions}

To capture the profitability consequences of marketing investment costs the ADBUDG based function expressed by Eq. (2) needs to be calibrated. Once this function is calibrated for each of the drivers (i.e., quality elements), we automatically obtain an estimate for the total investment effort as reflected by Eq. (3). To calibrate the function between investment effort $\left(e f f_{i}\right)$ and drivers $\left(y_{i}\right)$ as captured by Eq. (2), we first need to understand what actions are capable of influencing the customer's perceptions regarding these drivers. Interviews with the company's customer service managers and several customers yielded insight in this matter. Second, we need to assess how various levels of these actions, reflecting different investment effort levels, relate to changes in the customer's perceptions of the various drivers (i.e., rating shifts). As shown in Appendix A a set of standard questions is asked to determine the shape of the function (i.e., ADBUDG parameters $c_{i}$ and $d_{i}$ ) between investment effort and the driver perceptions (see also the original work of Little (1970) or the more recent application of Dong, Swain, and Berger (2007)).

For reasons of confidentiality, an example cost-function is used in the current application of our decision-making model. As each practical application of our model is likely to have a unique costfunction reflecting the idiosyncrasies of each setting, the use of an example cost-function does not limit the applicability of our model. Regarding the current application, parameter $c_{i}$ was set to 1 , thereby reflecting that the investments aimed improving customers' quality perceptions are subject to diminishing returns (Little, 1970). For parameter $d_{i}$ a value of $\$ 50,000$ was chosen to approximate the underlying cost function. Finally, as the purpose of parameters $a_{i}$ and $b_{i}$ is to restrict changes in $y_{i}$ to a meaningful range, these parameters are implicitly determined by the endpoints of the scales used to measure the customer's perceptions concerning the various drivers. Consequently, parameter $a_{i}$ is set to 1 (the lowest value of the measurement scale used) and parameter $b_{i}$ is set to 11 (the highest value of the measurement scale used).

\subsection{Investment strategy}

Rust, Moorman, and Dickson (2002) conclude that financial returns on marketing investments can arise from increasing revenues by increasing satisfaction, decreasing costs, or both. Furthermore, investment profitability may vary as a function of retaining current customers and/or gaining new customers (Rust et al., 2004). Although many investment strategies are possible and no company can afford to ignore both customer acquisition and cost reduction in favor of respectively customer retention and revenues, the current application demonstrates the optimization of marketing investment profitability as a result of increasing revenues due to enhanced customer retention. This choice is based on Rust et al. (2002) who show that revenue expansion due to increased satisfaction yields superior results over cost reduction strategies. Furthermore, the work of Fornell and Wernerfelt (1987, 1988) evidences that customer retention is an economically more feasible strategy than customer acquisition. Despite the focus on revenue expansion through customer retention, the final section of this paper elaborates how our optimization framework can be adapted to accommodate other situations such as designing optimal investment strategies for both customer retention and acquisition.

Below the results regarding the application of our decision-making model are outlined. The software package AIMMS ${ }^{4}$ was used to

\footnotetext{
${ }^{4}$ AIMMS stands for Advanced Interactive Mathematical Modeling Software for more information see also www.aimms.com and Appendix A to this paper.
} 
Table 5

Optimal investment strategies.

\begin{tabular}{|c|c|c|c|c|c|c|c|}
\hline & Qual1 $\left(y_{1}\right)$ & Qual2 $\left(y_{2}\right)$ & Qual3 $\left(y_{3}\right)$ & Qual4 $\left(y_{4}\right)$ & Qual5 $\left(y_{5}\right)$ & Qual6 $\left(y_{6}\right)$ & Qual7 $\left(y_{7}\right)$ \\
\hline $\begin{array}{l}\text { Short description } \\
\text { of driver }\end{array}$ & $\begin{array}{l}\text { Ordering } \\
\text { (e.g. accessibility) }\end{array}$ & $\begin{array}{l}\text { Information requests } \\
\text { (e.g. knowledge employees) }\end{array}$ & $\begin{array}{l}\text { Catalogue } \\
\text { (e.g. accessibility) }\end{array}$ & $\begin{array}{l}\text { Delivery } \\
\text { (e.g. timeliness) }\end{array}$ & $\begin{array}{l}\text { Product related quality } \\
\text { (e.g. assortment) }\end{array}$ & $\begin{array}{l}\text { Complaint management } \\
\text { (e.g. first time fix) }\end{array}$ & $\begin{array}{l}\text { Invoicing } \\
\text { (e.g. clarity) }\end{array}$ \\
\hline $\begin{array}{l}\text { Pre-investment } \\
\text { level of driver }\end{array}$ & 7.82 & 7.61 & 6.97 & 6.5 & 6.5 & 7.52 & 7.49 \\
\hline $\begin{array}{l}\text { Effort to main } \\
\text { current level }\end{array}$ & $\$ 179,358$ & $\$ 159,205$ & $\$ 115,017$ & $\$ 92,857$ & $\$ 92,857$ & $\$ 151,613$ & $\$ 149,203$ \\
\hline $\begin{array}{l}\text { Average impact of } \\
\text { driver on retention } \\
\text { probability for customer } c\end{array}$ & 0.0164 & 0.0191 & 0.0103 & 0.0133 & 0.0187 & 0.0135 & 0.0149 \\
\hline \multicolumn{8}{|l|}{ Optimal total effort level $\$ 42,000$} \\
\hline $\begin{array}{l}\text { Optimal allocation } \\
\text { over drivers }\end{array}$ & $0 \%$ & $0 \%$ & $0 \%$ & $16.94 \%$ & $83.06 \%$ & $0 \%$ & $0 \%$ \\
\hline Optimal effort level & $\$ 0$ & $\$ 0$ & $\$ 0$ & $\$ 7114$ & $\$ 34,886$ & $\$ 0$ & $\$ 0$ \\
\hline $\begin{array}{l}\text { Post-investment } \\
\text { level of driver }\end{array}$ & 7.82 & 7.61 & 6.97 & 6.67 & 7.19 & 7.52 & 7.49 \\
\hline $\begin{array}{l}\text { Change in level } \\
\text { of driver }\end{array}$ & 0 & 0 & 0 & 0.17 & 0.69 & 0 & 0 \\
\hline \multicolumn{8}{|c|}{ Budget constraint of $\$ 10,000$ total effort level } \\
\hline $\begin{array}{l}\text { Optimal allocation } \\
\text { over drivers }\end{array}$ & $0 \%$ & $0 \%$ & $0 \%$ & $0 \%$ & $100 \%$ & $0 \%$ & $0 \%$ \\
\hline Optimal effort level & 0 & 0 & 0 & 0 & $\$ 10,000$ & 0 & 0 \\
\hline $\begin{array}{l}\text { Post-investment } \\
\text { level of driver }\end{array}$ & 7.82 & 7.61 & 6.97 & 6.5 & 6.73 & 7.52 & 7.49 \\
\hline $\begin{array}{l}\text { Change in level } \\
\text { of driver }\end{array}$ & 0 & 0 & 0 & 0 & 0.23 & 0 & 0 \\
\hline
\end{tabular}

perform all optimization analyses. More specifically we opted for a subgradient optimization method. Furthermore, in demonstrating the applicability of our optimization framework two alternative situations are presented. First, no limit is assumed on available investment resources, that is, the budget restriction is relaxed. Second, the use of our decision-making approach in situations where there is a budget constraint is demonstrated. Overall, the use of our decision-making framework will proceed in exactly the same manner regardless of whether a budget constraint is imposed or not.

\subsection{Optimal level of investment effort}

Coherent with Rust et al. (1995) idea that marketing investments should be optimized rather than maximized, the concave relationship between investment effort and investment profitability for the current application presented in Fig. 2 further underscores the need to carefully balance costs and revenues when evaluating marketing investments. Put differently, Fig. 2 illustrates that it is possible to overinvest in marketing initiatives in terms of profitability and that an

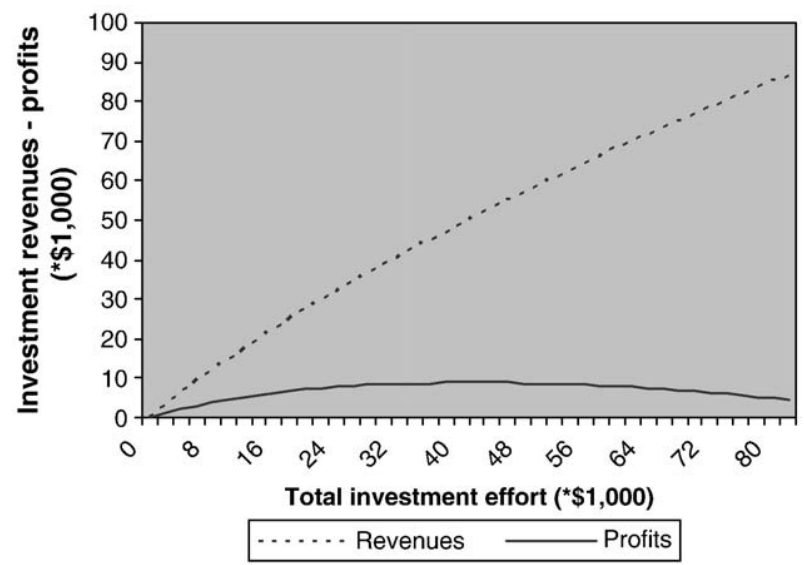

Fig. 2. Investment effort, investment revenues, and investment profitability. optimal investment level yielding a maximum investment profitability exists.

Our decision model can be used as follows to determine this optimal investment level. Analytically, the optimal investment level follows from the derivative of our profit function. In general, marketing investments remain economically feasible as long as the derivative of the profit function is larger than or equal to zero. The optimal investment level is reached when this derivative equals zero. Setting the derivative of the profit function equal to zero and solving this equation for the situation at hand, shows that an optimal investment level of $\$ 42,000$ yields a maximum investment profitability level of $\$ 8894$.

It should be stressed that our decision-making model is not restricted to finding a maximum level of marketing investment profitability in situations where the amount of available investment resources is unlimited (i.e. no budget restriction applies). To further illustrate the versatility of our decision-making model, it is subsequently assumed that a business market manager has a limited budget of $\$ 10,000$ available for making marketing investments. Our approach is also suitable for addressing the issue of how to get the most out of this restricted amount of resources. Running our optimization model with the budget constraint set to $\$ 10,000$ points out that this budget can lead to a maximum marketing investment profitability level of $\$ 4480$.

As our decision-making approach clearly and directly provides estimates of the level of investment effort needed to realize a certain level of profitability, the rate of return of investment ${ }^{5}(R O I)$ can be computed as shown in Eq. (8).

$R O I=\left(\frac{\text { profits-tot.effort }}{\text { tot.effort }}\right) * 100 \%$

\footnotetext{
5 Please note that the formula to assess the rate of return on investment does not exclude the use of more advanced calculations such as including the discounted residual value or using the discounted value of the cash flow in determining the rate of return. We would like to thank one of the reviewers for bringing this to our attention.
} 
Using Eq. (8) shows that the rates of return on investment are $21.18 \%$ and $44.80 \%$ for the situation without (i.e., investment level of $\$ 42,000$ ) and with (i.e., investment level of $\$ 10,000$ ) a budget constraint respectively.

\subsection{Optimal allocation of investment effort}

In addition to determining the optimal level of investment effort, an optimal allocation of this investment effort is equally important in maximizing investment profitability (Mantrala, Sinha, \& Zoltners, 1992). In deciding on the optimal allocation of the investment budget over the various drivers, the (derivative of the) profit function plays again a crucial role. In particular, the optimal allocation of investment effort $\sum_{i \in I}\left(e f f_{i}-e f f(0)_{i}\right)$ over the different drivers $y_{i}$ is determined by the absolute and relative magnitude of the partial derivatives of the profit function with respect to various effort levels effi $i$ needed to improve the different drivers.

In general terms our model determines the optimal allocation of the available investment budget effort as follows. Any optimal allocation starts with assigning all available investment effort to the driver for which the partial derivative of the profit function with respect to investment effort eff $f_{i}$ is highest, say driver $p$. Eventually each partial derivative decreases, reflecting diminishing returns on investment. As such, the partial derivative with respect to eff $p$ at some stage will equal the partial derivative with respect to $\operatorname{eff}_{q}$. Here driver $q$ is the driver for which the partial derivative of the profit function with respect to effort is overall second highest. Upon reaching this equilibrium of partial derivatives, the optimal allocation is maintained by dividing the remaining available investment effort over both drivers $p$ and $q$ in such proportions that the partial derivatives of the drivers remain equal. This proportion depends on the ADBUDG parameters $a_{i}, b_{i}, c_{i}$, and $d_{i}$, and the impact of each driver on investment profitability, $\lambda_{y_{1}, \text { loyc }}$. This process of comparing the profit function's partial derivatives belonging to the different drivers continues until the entire budget is spent.

For the situation at hand it is now demonstrated how the optimal investment level determined previously needs to be allocated to indeed achieve the maximum level of investment profitability. To do this, the optimization framework presented in Exhibit 1 is re-run, setting the budget constraint equal to $\$ 42,000$ (i.e., optimal investment effort level). The results of this analysis are presented in Table 5. Likewise, the optimal allocation of resources for the situation in which there is only a limited budget of $\$ 10,000$ available for marketing investments is determined (see also Table 5).

The model results on the optimal allocation of investment efforts presented in Table 5 reveal the following. In the situation in which there is a boundless investment budget to obtain the overall marketing investment profitability maximum (i.e., an investment budget of $\$ 42,000$ ), the maximum investment profitability level of $\$ 8894$ is obtained if $16.94 \%$ of the budget (or $\$ 7.114$ ) is allocated to improving customer perceptions regarding the driver $y_{4}$ "delivery" and $83.06 \%$ of the budget (or $\$ 34.886$ ) is allocated to improving customer perceptions regarding driver $y_{5}$ "product related quality". Turning to the situation in which a limited investment budget of $\$ 10,000$ is assumed, our model indicates that the maximum possible level of marketing investment profitability (\$4480) is obtained when the entire budget is directed at improving the driver $y_{5}$ "product related quality". These allocation schemes are optimal in the sense that all investment effort allocation schemes that differ from the derived optimal allocation scheme yield lower investment profitability levels than the projected maximum level of $\$ 8894$ (effort level of $\$ 42,000$ ) and $\$ 4480$ (effort level of $\$ 10,000$ ) respectively.

Finally, to translate the suggested amounts aimed at improving the different drivers into concrete actions, the input data used to calibrate the relationship between customer driver perceptions and invest- ment costs (see also ADBUDG function in Eq. (2)) should be used for interpolation. For example, the $\$ 7114$ suggested to improve driver $y_{4}$ "delivery" could correspond with closing contracts with a logistics services company to ensure emergency on-time delivery when necessary.

\subsection{Investment risk}

All (marketing) investments entail uncertainty as the actual financial returns may differ from what was predicted or expected. Consequently, thorough decision making regarding (marketing) investments requires evaluating the projected returns in light of this uncertainty or risk. As risk is reflected by the variability of financial returns (Brealey \& Myers, 2000), examining the robustness of the projected profitability as a function of changes in the optimization framework's parameters provides an excellent way to assess the level of risk associated with the marketing investment decisions.

Comparable to the notion of risk as variability in returns, the robustness of the solution refers to the variation in the projected optimal financial returns and the financial returns that can be expected under a different set of parameters in the optimization framework. An operations research technique that is particularly valuable in assessing the variability or robustness of the financial returns predicted by our optimization framework is nominal range sensitivity analysis (Morgan \& Henrion, 1990; von Winterfelt \& Edwards, 1986). Below it is demonstrated how this technique can be applied to assess the robustness or risk of the projected investment schemes.

Nominal range sensitivity analysis evaluates the effects on a model's output due to changes exerted by varying individual model parameters across a range of plausible values while keeping the other parameter values at the nominal or base-case values. The robustness of the model is subsequently expressed as the positive or negative percentage change compared to the nominal solution (Frey \& Patil, 2002). For the situation at hand, nominal range sensitivity analysis is used to assess how the projected optimal solution differs as a function of changes in the parameters of the model explaining the relationship dynamics. ${ }^{6}$

Regarding the set of structural relationships connecting the input variables $y_{i}$ to $l o y_{c}$, the impact of a change in one of the structural model's relationships can be determined as follows. If the weight of a certain relation $(k, l)$ is changed, say from $w_{k l}$ to $w_{k l}^{\prime}=w_{k l}+\delta$, and all other relations remain unchanged, i.e., $w_{i j}^{\prime}=w_{i j}((i, j) \neq(k, l))$ parameter $y_{p, q}$ describing the influence of driver $z_{p}$ on outcome variable $z_{q}$ as expressed by Eq. (7) changes to $\lambda_{p, q}^{\prime}$ as expressed by Eq. (9). Please see Appendix A for the complete derivation of Eq. (9).

$\lambda_{p, q}^{\prime}=\lambda_{p, q}+\lambda_{p, k} \lambda_{l, q} \delta$

Using Eq. (9) the projected investment profitability for various level of $\delta$ and compare these figures to the initial optimal investment profitability is determined. In calculating the projected profitability level as a function of $\delta$, the investment level and investment allocation scheme that were considered optimal when initially solving the optimization model is used. Table 6 below summarizes the results for the nominal range sensitivity analysis for the situation at hand.

Based on the outcomes of the sensitivity analysis, business market managers can see how much the projected marketing investment

\footnotetext{
${ }^{6}$ For assessing the robustness of the solution due to changes in the cost function or the dynamic regression equation used to model the customer monetary value a similar procedure can be followed.
} 
Table 6

Sensitivity analysis.

\begin{tabular}{|c|c|c|c|c|c|c|}
\hline \multirow[t]{2}{*}{ Path } & \multicolumn{3}{|l|}{$w_{i j}-5 \%$} & \multicolumn{3}{|l|}{$w_{i j}-5 \%$} \\
\hline & $\begin{array}{l}\text { Investment } \\
\text { profitability }\end{array}$ & $\%$ & ROI (\%) & $\begin{array}{l}\text { Investment } \\
\text { profitability }\end{array}$ & $\%$ & ROI (\%) \\
\hline Qual1 $\rightarrow$ Quality & $\$ 11,984$ & 35 & 28.51 & $\$ 4136$ & 53 & 9.85 \\
\hline Qual2 $\rightarrow$ Quality & $\$ 11,794$ & 33 & 28.08 & $\$ 6230$ & 30 & 14.83 \\
\hline Qual3 $\rightarrow$ Quality & $\$ 10,196$ & 15 & 24.28 & $\$ 7640$ & 14 & 18.19 \\
\hline Qual4 $\rightarrow$ Quality & $\$ 10,596$ & 19 & 25.23 & $\$ 7286$ & 18 & 17.35 \\
\hline Qual5 $\rightarrow$ Quality & $\$ 9614$ & 8 & 22.89 & $\$ 8185$ & 8 & 19.49 \\
\hline Qual6 $\rightarrow$ Quality & $\$ 10,969$ & 23 & 26.12 & $\$ 6940$ & 22 & 16.52 \\
\hline Qual7 $\rightarrow$ Quality & $\$ 11,018$ & 24 & 26.23 & $\$ 6900$ & 22 & 16.43 \\
\hline Quality $\rightarrow$ Value & $\$ 16,982$ & 91 & 40.43 & $\$ 2594$ & 71 & 6.18 \\
\hline Quality $\rightarrow$ Satisfaction & $\$ 15,617$ & 76 & 37.18 & $\$ 3929$ & 56 & 9.35 \\
\hline Value $\rightarrow$ Satisfaction & $\$ 14,124$ & 59 & 33.63 & $\$ 4691$ & 47 & 11.17 \\
\hline Satisfaction $\rightarrow$ Trust & $\$ 10,429$ & 17 & 24.83 & $\$ 6730$ & 24 & 16.02 \\
\hline Value $\rightarrow$ Trust & $\$ 14,270$ & 61 & 33.98 & $\$ 3938$ & 56 & 9.38 \\
\hline Value $\rightarrow$ Loyalty & $\$ 13,556$ & 53 & 32.28 & $\$ 4580$ & 48 & 10.90 \\
\hline Satisfaction $\rightarrow$ Loyalty & $\$ 14,447$ & 63 & 34.40 & $\$ 2945$ & 67 & 7.01 \\
\hline Trust $\rightarrow$ Loyalty & $\$ 15,900$ & 79 & 37.86 & $\$ 3238$ & 64 & 7.71 \\
\hline
\end{tabular}

profitability deviates from the original optimal profitability level as a function of changes in the decision-making model's parameters. Together with the expected return on investment of the original optimal solution, the outcomes of the sensitivity analysis provide the required information to make a risk-return trade-off for particular marketing investment initiatives.

\section{Discussion and implications}

Building on relationship marketing theory and operations research techniques, the aim of this study was to develop a decision-making approach that enables business market managers to effectively manage customer relationships in both a customer-oriented and economically justified manner. Regarding the intended contribution of our work, the following elements can be discerned. First, a general applicable decision-making or optimization framework to assess critical management issues related to evaluating and optimizing marketing investments is developed and demonstrated. Second, the concept of sensitivity analysis to assess and understand marketing investment risk is introduced.

In line with these two contributions, it needs to be emphasized that although the optimization of marketing efforts to strengthen customer-firm relationship is an often-stated management goal, little work exists on how this can be actually achieved in both a customeroriented and economically sound manner. This is especially relevant as maximizing financial performance involves optimizing customer perceptions rather than maximizing them. Therefore, the development of our decision-making approach is a logical evolutionary next step in the area of return on marketing initiated by the seminal work of Rust et al. (1995).

In terms of managerial implications our decision-making framework is believed to positively impacts business marketing practice in the following ways. First, our optimization framework provides a clear-cut answer to the key managerial issues of how much to invest and how to allocate these resources in order to maximize marketing investment profitability. Moreover, as a consequence of explicitly balancing the costs and benefits of marketing investments the accompanying rate of return on investment can be readily computed. Besides the informative value of the return on investment figure in isolation, the rate of return stemming from our optimization framework can be compared with alternative and competing investment opportunities such as the purchase of a new piece of equipment. Second, we show how sensitivity analysis of the optimal solution provides a proxy for risk. Consequently, our approach enables decision makers to form a well-informed risk- return trade-off when evaluating different and possibly competing investment opportunities to get the most of their scarce resources. Third, in terms of implementing our decision-making framework in practice it should be stressed that the input needed to calibrate the various elements of the framework are in close reach of the company. Data on customer perceptions necessary to model the investment revenues are often already collected by companies on a regular basis, whereas data on customer monetary value is typically readily available in the companies' internal records. Furthermore, the calibration of the ADBUDG function to link investment efforts to marketing investment drivers follows well established lines and requires a relatively limited amount of qualitative research. Fourth, our decision-making approach can be used to evaluate and compare different (marketing) investments. Although the main focus of the current paper was on optimizing investment effort and allocation to maximize profitability without imposing a budget constraint, the application of the framework is not limited to this condition. The optimization analysis can be conducted regardless of the available level of investment effort (i.e., investment budget) by imposing a budget constraint. Furthermore, besides searching for an optimal solution, the framework can also be used to evaluate and compare the financial consequences of different (marketing) investment initiatives. Fifth, even though the (financial) data used to calibrate the optimization framework is specific for each company, the structure of the model and its various elements are generally applicable. As will be shown in the next section, the general structure of our decision-making approach can be easily adapted to situations other than those demonstrated here.

\section{Limitations and extensions of the optimization framework}

Part of the strength of a research project lies in the recognition of its limitations. Although the principal purpose of our empirical study (see also section three) is to serve as a means to demonstrate our decision-making approach, it is relevant to acknowledge that the current sample is not strong enough to draw conclusions on the customer-firm relationship dynamics in business markets in general. More specifically, the fact that data were used from a single company together with the relatively small sample size and its narrow focus seriously limits the generalizability of our empirical findings regarding customer relationship management theory in business settings. Other limitations also include the restricted focus on customer retention for a single company/brand, the exclusion of possible customer differences regarding the various elements of our optimization framework, and the unavailability of data to model longitudinal effects. Furthermore, we did not account for the possible impact of switching costs in explaining customer loyalty intentions. Although probably of minor concern in the current setting, switching costs may be an important determinant of loyalty intentions as evidenced by the work of Han and Sung (2008).

Despite these limitations it might be interesting to show how our optimization model can be extended to incorporate these issues. Building on the work of Blattberg, Getz, and Thomas (2001) the revenue function in our framework can be extended to include the effects of new customer acquisition. Furthermore, similar to the work of Rust et al. (2004) brand switching effects can be incorporated in our optimization framework by using a switching matrix rather than the customer's retention probability. Likewise, the model used to explain customer loyalty may be extended to include elements such as perceived switching costs. Customer heterogeneity may be explicitly modeled by using specific analysis techniques such as random effects models or MCMC models to estimate the revenue part and subsequently integrate these equations in the optimization model. Third and final, marketing investment efforts may differ in their degree of persistence in influencing marketing investment drivers. On one hand there are investments, such as a computer for 
better information processing that once it is done, its effect on customer evaluative judgments persists during the succeeding periods. On the other hand, there are marketing initiatives such as investments in staff for which the effects on customer evaluative judgments are reduced once the staff is replaced. To account for these temporal effects the ADBUDG function can be extended with a persistence factor $\kappa$, which is high for investments that have a long lasting effect, and low for investments that have a short-term effect only.

\section{Conclusion}

The aim of relationship marketing is to build customer-firm relationships that benefit both parties. In order to achieve this, there is a great need for management tools that quantify both the positive and negative consequences of marketing investments directed at building mutually beneficial customer-firm relationships. The decision-making framework put forward in this paper offers business market managers a tool to manage marketing investments in both an economically justified and customer-oriented manner. As one of the few existing studies that combine operations research techniques with relationship marketing knowledge in designing a marketing investment decisionmaking approach, we believe that our work contributes to both business marketing practice and research. In particular, our paper extensively shows how our decision-making approach can be used to assess key marketing investment decision issues such as the amount of effort needed to optimize profitability, the calculation of the rate of return on investment, and the design of an optimal investment resource allocation scheme.

\section{Appendix A}

Appendix A contains additional computational details concerning the application of our decision-making model.

\section{Modeling the marketing investment revenues function}

The two main elements in our marketing revenues function are customer c's probability to remain loyal over a time period and his monetary value over that period. Below we outline how we estimated both elements of the revenue function.

\section{Probability to remain loyal}

To include a set of non-recursive structural relationships describing a particular behavioral process in a mathematical decision-making or optimization model the following procedure applies. First, estimate the model describing the relevant relationships among key constructs using SEM or regression-based techniques. Second, use network analysis to determine the total influence of input variable or driver $z_{p}$ on a particular outcome variable $z_{q}$. Here, the following principles apply. For a non-recursive (acyclic) model in which the variables are indexed in a way that all relations are of the type $\left(z_{i}, z_{j}\right)(i<j)$, i.e., only lower indexed variables influence higher indexed variables (Ahuja, Magnanti, \& Orlin, 1993), the influence of any variable on any other variable can be expressed as presented below in Eq. (A1.1). If we denote the change in each variable $z_{i}(i<j)$ by $\Delta z_{i}$, then

$\Delta z_{j}=\sum_{i<j:(i, j) \in A} w_{i j} \Delta z_{i}$

For computing the total influence of driver $z_{p}$ on outcome variable $z_{q}$ consider all paths connecting $z_{p}$ to $z_{q}$, and determine the sum of the lengths of these paths. The length of each path is given by the product of the weights of the separate arcs of the path. In mathematical terms, the calculation of the total influence of $z_{p}$ on $z_{q}$, denoted by $\lambda_{p, q}$, is expressed below in Eq. (A1.2).

$\lambda_{p, q}=\sum_{P:\left(z_{p} \rightarrow z_{q}\right)}\left(\prod_{\left(z_{i}, z_{j}\right) \in P} w_{i j}\right)$

In Eqs. (A1.1)-(A1.2) $w_{i j}$ are the different marginal effects of the relevant independent variables on the relevant dependent variables in the set of structural relationships. Please note that the computation of the relevant marginal effects depends on the functional form of the equation.

\section{Customer monetary value}

Data on customer monetary value typically have a panel design, implying that data is collected across individuals over time. To estimate these models the data needs to be constructed as having NT rows where $N$ denotes the number of respondents and $T$ are the various time periods over which we collected information about the respondents. To model the data at hand we opted for a dynamic panel data model. Dynamic panel data models are characterized by the presence of a lagged dependent variable among the regressors and are generally expressed as:

$y_{c t}=\delta y_{c, t-1}+x_{c t}^{\prime} \beta+u_{c t} \quad c=1, \ldots, N ; t=1, \ldots, T$

Where $y_{c t}$ denotes the score on variable $y$ of respondent $c$ at time $t$, $x_{c t}$ are the scores of the $c$ th respondent on $K$ regressors at time $t, \delta$ and $\beta$ are regression coefficients, and $u_{c t}$ is the model's error component. In modeling panel data the following aspects need to be considered carefully.

First of all, due to the inclusion of a lagged-dependent variable as independent variable the assumption of exogeneity no longer may hold. To alleviate the effects of endogeneity Baltagi (2008) advises to replace the dependent variable $y_{c t}$ by its first difference specification $\Delta y_{c t}=y_{c t}-y_{c, t-1}$ and to use $y_{c, t-2}$ as an instrument for the lagged dependent variable regressor. Second, in contrast to regular crosssectional regression models, the disturbance term $u_{c t}$ in panel data regression models may consist of the following elements: a timeinvariant unobservable individual specific effect $\mu_{c}$, an individualinvariant time effect $\lambda_{t}$, and random remainder error $v_{c t}$. Depending on whether $\lambda_{t}$ is equal to zero or not, a one-way error component model $\left(u_{c t}=\mu_{c}+v_{c t}\right)$ or a two-way error component model $\left(u_{t}=\mu_{c}+\right.$ $\left.\lambda_{t}+v_{c t}\right)$ applies respectively. A Breusch-Pagan Lagrange multiplier test formally assesses whether the hypothesis of $\lambda_{t}$ being equal to zero is rejected or not. Finally, the parameter reflecting the time-invariant individual specific effect, $\mu_{c}$, can be either modeled as a fixed or random effect. A Hausman specification test can be performed to assess whether a fixed or random effects model specification is preferred.

\section{Modeling the marketing investment cost function}

The relationship between investment effort and the level of the drivers is modeled using the ADBUDG model suggested by Little (1970). This model offers a simple and flexible tool to calibrate a variety of S-shaped or concave response functions. The general form of the ADBUDG-function describing the relationship between effort $\left(e f f_{i}\right)$ and response $y_{i}$ is defined as follows:

$y_{i}=a_{i}+\left(b_{i}-a_{i}\right) \frac{e f f_{i}^{c_{i}}}{d_{i}+e f f_{i}^{c_{i}}}$

Where:

$y_{i} \quad$ Perceptual variable at which effort is directed/driver

eff $f_{i} \quad$ Investment effort in \$ 
$a_{i} \quad$ Minimum value of $y_{i}$ when $e f f_{i}=0$

$b_{i} \quad$ Upper asymptote of scale assessing $y_{i}$ (corresponds with eff $\rightarrow \rightarrow \infty$ )

$c_{i} \quad$ Parameter determining shape of response function. Function is concave when $0<c_{i}<1$ and $S$-shaped when $c_{i}>1$

$d_{i} \quad$ Parameter determining shape of response function

Given that the model has only four parameters, only four data points are necessary to calibrate the function in Eq. (A1.4). Those four parameters are determined based on interviews with the decisionmakers and/or the people at whom the efforts are directed (e.g., customers). Typically, these interviews focus on the following four questions:

1) Regarding $i$ what is the current level of effort $\left(e f f_{i}\right)$ and to what evaluation does that lead $\left(y_{i}\right)$ ? This point corresponds to $\left(e f f(0)_{i}, y\right.$ $(0)_{i}$ ) on the ADBUDG response curve.

2) If effort eff $f_{i}$ is reduced to 0 what will then be the evaluation regarding $y_{i}$ ? This provides the value for parameter $a_{i}$. Usually, $a_{i}$ reflects the lowest value of the scale on which the perceptions are measured.

3) If effort effi $f_{i}$ approaches infinity what will then be the value of $y_{i}$ ? This answer provides the value for parameter $b_{i}$. Usually, $b_{i}$ reflects the highest value of the scale on which the perceptions are measured.

4) If, compared to the current situation effort, eff $(0)_{i}$ is doubled to what level of $y_{i}$ would that lead?

\section{The derivative of the profit function}

The derivative of the profit function plays a pivotal role in optimizing marketing investment profitability in terms of the optimal investment effort level and the optimal allocation of investment effort. Without engaging in the complex and tedious process of specifying the exact specification of the derivative of the profit function, the following paragraph provides sufficient information to obtain insight into the role the derivative of the profit function plays in the optimization analysis. Please note that we disregard below the investments needed to maintain the status quo for the sake of simplicity.

The marketing investment profit function is a composite function of the marketing investment revenue function and the marketing investment cost function. As can be clearly seen in Exhibit 1, the dependent variable $l o y_{c}$ in the marketing investment revenues equation is a function of the different drivers $y_{i}$, which in turn are a function of marketing investment effort eff $f_{i}$ as implied by the ADBUDG-model. Thus, $\operatorname{lo}_{c}$ is both a function of intermediate variables $y_{i}$ and independent variables eff $f_{i}$. According to the chain rule, the derivative of the marketing investment profit function with respect to eff $f_{i}$ is in the format of $\partial$ profit $/ \partial e f f_{i}=\left(\left(\partial p r o f i t / \partial y_{i}\right) \cdot\left(\partial y_{i} / \partial e f f_{i}\right)\right)-1$. That is, the derivative of the profit function with respect to eff $i$ is a function of the derivative of the profit function with respect to $y_{i}$ and the derivative of $y_{i}$ with respect to eff $f_{i}$. The term -1 arises from the fact that the total investment effort function is a constant term. The derivative of the profit function with respect to $y_{i}$ depends on the magnitude and functional form of the relationships connecting $\operatorname{loy}_{c}$ and $y_{i}$ (proof of the diffentiability of the revenue function can be obtained from the authors upon request). The derivative of $y_{i}$ with respect to eff $f_{i}$ equals $\left(c_{i} d_{i} b_{i} e f f_{i}^{c_{1}-1}-c_{i} d_{i} a_{i} e f f_{i}^{c_{i}-1}\right)\left(d_{i}+e f f_{i}^{f_{i}}\right)^{-2}$ implying that this derivative depends on all ADBUDG-parameters.

As long as $\partial p r o f i t / \partial e f f_{i} \geq 0$ investments remain feasible as the incremental investment revenues outweigh the incremental investment efforts.

\section{Sensitivity analysis}

Mathematically, the notion of nominal range sensitivity analysis is as follows. If the weight of a certain relation $(k, l)$ is changed, say from $w_{k l}$ to $w_{k l}^{\prime}=w_{k l}+\delta$, and all other relations remain unchanged, i.e., $w_{i j}^{\prime}=w_{i j}((i, j) \neq(k, l))$ parameter $\lambda_{p, q}$ describing the influence of driver $z_{p}$ on outcome variable $z_{q}$ as expressed by Eq. (A1.2) changes to $\lambda_{p, q}^{\prime}$ as follows.

$$
\begin{aligned}
\lambda_{p, q}^{\prime} & =\sum_{P:\left(z_{p} \rightarrow z_{q}\right)}\left(\prod_{\left(z_{i}, z_{j}\right) \in P} w_{i j}^{\prime}\right) \\
& =\sum_{P:\left(z_{p} \rightarrow z_{q}\right):(k, l) \in P}\left(\prod_{\left(z_{i}, z_{j}\right) \in P} w_{i j}^{\prime}\right)+\sum_{P:\left(z_{p} \rightarrow z_{q}\right):(k, l) \in P}\left(\prod_{\left(z_{i}, z_{j}\right) \in P} w_{i j}^{\prime}\right) \\
& =\sum_{P:\left(z_{p} \rightarrow z_{q}\right):(k, l) \in P}\left(\prod_{\left(z_{i}, z_{j}\right) \in P} w_{i j}\right)+\sum_{P:\left(z_{p} \rightarrow z_{q}\right):(k, l) \in P}\left(\prod_{\left(z_{i}, z_{j}\right) \in P-(k, l)} w_{i j}\right)\left(w_{k l}+\delta\right) \\
& =\sum_{P:\left(z_{p} \rightarrow z_{q}\right):(k, l) \in P}\left(\prod_{\left(z_{i}, z_{j}\right) \in P} w_{i j}\right)+\sum_{P:\left(z_{p} \rightarrow z_{q}\right):(k, l) \in P}\left(\prod_{\left(z_{i}, z_{j}\right) \in P} w_{i j}\right)+\sum_{P:\left(z_{p} \rightarrow z_{q}\right):(k, l) \in P}\left(\prod_{\left(z_{i}, z_{j}\right) \in P-(k, l)} w_{i j}\right) \delta
\end{aligned}
$$

The first two terms in the last row of Eq. (A1.5) add up to $\lambda_{p, q}$, whereas the last term (excluding parameter $\delta$ ) in the last row of Eq. (A1.5) can be written as:

$$
\begin{aligned}
& \sum_{P:\left(z_{p} \rightarrow z_{q}\right):(k, l) \in P}\left(\prod_{\left(z_{i}, z_{j}\right) \in P-(k, l)} w_{i j}\right)=\sum_{P:\left(z_{p} \rightarrow z_{q}\right)}\left(\prod_{\left(z_{i}, z_{j}\right) \in P} w_{i j}\right) \\
& \quad \times \sum_{P:\left(z_{p} \rightarrow z_{q}\right)}\left(\prod_{\left(z_{i}, z_{j}\right) \in P} w_{i j}\right)=\gamma_{p, k} \cdot \gamma_{l, q}
\end{aligned}
$$

Thus, substituting Eq. (A1.6) for the corresponding term in Eq. (A1.5) yields the following expression (see Eq. (A1.7)) to calculate the influence of driver $z_{p}$ on outcome variable $z_{q}$ as a function of changes in the structural model parameters.

$\lambda_{p, q}^{\prime}=\lambda_{p, q}+\lambda_{p, k} \lambda_{l, q} \delta$

Using the optimal investment effort allocation scheme, compute the marketing investment profitability obtained with $\lambda_{p, q}^{\prime}$. Now, the robustness of the optimal solution is obtained by computing the relative difference in investment profitability obtained for parameters $\lambda_{p, q}$ (original coefficients) and $\lambda_{p, q}^{\prime}$ (altered coefficients). The robustness of the optimal solution is defined as $\left[\frac{\left|\operatorname{profit}\left(\lambda_{p, q}\right)-\operatorname{profit}\left(\lambda_{p, q}^{\prime}\right)\right|}{\operatorname{profit}\left(\lambda_{p, q}\right)}\right] * 100 \%$. Note that in assessing the robustness of the optimal solution, total profit is used rather than investment profit.

Regarding the situation described in the paper, for which we have nonlinear structural relationships underlying the revenue generating process and thus the marketing investment profitability calculation, the effect of changes in the model parameters (the $\delta$ parameter in the sensitivity analysis) on the outcome variable is not constant per respondent. Consequently, the function to determine the marketing investment profitability under $\lambda_{p, q}^{\prime}$ contains a separate $\lambda_{p, q}^{\prime}$ parameter for each respondent.

\section{Optimization software}

Our decision-making model was programmed in AIMMS. This software package was subsequently used to run all optimization analyses in this paper. AIMMS is an advanced development environment for building optimization based operation research applications and is used by leading companies throughout the world to support many different aspects of decision making.

For the purpose of this paper all programming was done in the mathematical programming language that is originally used in AIMMS. However, very recently AIMMS developed an add-in for 
Microsoft Excel allowing to run optimization analyses like the ones described in this paper in an Excel setting. This development makes the practical application of our marketing investment decisionmaking tool more accessible and attractive for prospective users.

\section{Appendix B. Practical implementation of the decision-making approach}

The aim of Appendix B is to provide guidance for the practical implementation of the proposed decision-making approach. More specifically, without restricting ourselves to a specific programming language Appendix B explains in very simple terms (i.e. minimum of mathematical notation) the steps that are involved in using our decision-making approach. The explanation below describes the practical implementation on two different levels. First, the implementation in general terms. Second, a simple example model is used to further clarify the practical implementation in the gray areas.

The complete second appendix is available electronically from the corresponding author. Contact Sandra Streukens at sandra. streukens@uhasselt.be.

\section{References}

Ahuja, R. K., Magnanti, T. L., \& Orlin, J. B. (1993). Network flows: Theory, algorithms, and applications. Englewood Cliffs, NJ: Prentice Hall.

Anderson, E. W., Fornell, C., \& Lehmann, D. R. (1994). Customer satisfaction, market share, and profitability: Findings from Sweden. Journal of Marketing, 58(3), 53-66.

Anderson, E. W., \& Sullivan, M. W. (1993). Antecedents and consequences of customer satisfaction for firms. Marketing Science, 12(2), 107-120.

Baltagi, B. H. (2008). Econometric analysis of panel data. Chichester (UK): John Wiley \& Sons Ltd.

Blattberg, R., Getz, G., \& Thomas, J. S. (2001). Customer equity: Building and managing relationships as valuable assets. Boston, MA: Harvard Business School Press.

Blattberg, R. C., \& Hoch, S. J. (1990). Database models and managerial intuition: 50\% model + 50\% manager. Management Science, 36(8), 887-899.

Bolton, R. N. (1998). A dynamic model of the duration of the customer's relationship with a continuous service provider. Marketing Science, 17(1), 45-65.

Bolton, R. N., \& Drew, J. H. (1991). A multistage model of customers' assessment of service quality and value. Journal of Consumer Research, 17(4), 875-884.

Boudreau, J., Hopp, W., McClain, J. O., \& Thomas, L. J. (2003). On the interface between operations management and human resource management. Management Science, 5 (3), 179-202.

Brealey, R. A., \& Myers, S. C. (2000). Principles of corporate finance. New York, NY: McGraw-Hill College.

Bretthauer, K. M. (2004). Service management. Decision Sciences, 35(3), 325-332.

Cronin, J. J., Jr., Brady, M. K., \& Hult, G. T. (2000). Assessing the effects of quality, value, and customer satisfaction on consumer behavioral intentions in service environments. Journal of Retailing, 76(2), 193-218.

Diamantopoulos, A., \& Winklhofer, H. M. (2001). Index construction with formative indicators: an alternative to scale development. Journal of Marketing Research, 38 (2), 269-277.

Dodds, W. B., Monroe, K. B., \& Grewal, D. (1991). Effects of price, brand, and store information on buyers' product evaluations. Journal of Marketing Research, 28(3), 307-319.

Dong, W., Swain, S. D., \& Berger, P. D. (2007). The role of channel equity in customer equity management. Journal of Business Research, 60(12), 1243-1252.

Fornell, C., \& Wernerfelt, B. (1987). Defensive marketing strategy by customer complaint management: A theoretical analysis. Journal of Marketing Research, 24 (4), 337-346.

Fornell, C., \& Wernerfelt, B. (1988). A model for customer complaint management. Marketing Science, 7(3), 287-298.

Frey, H. C., \& Patil, S. R. (2002). Identification and review of sensitivity analysis methods. Risk Analysis: An International Journal, 22(3), 533-578.

Ganesan, S. (1994). Determinants of long-term orientation in buyer-seller relationships. Journal of Marketing, 58(2), 1-19.

Garbarino, E., \& Johnson, M. S. (1999). The different roles of satisfaction, trust, and commitment in customer relationships. Journal of Marketing, 63(2), 70-87.

Gök, O. (2009). Linking account portfolio management to customer information:Using customer satisfaction metrics for portfolio analysis. Industrial Marketing Management, 38(4), 283-299.

Gounaris, S. P. (2005). Trust and commitment influences on customer retention: Insights from business-to-business services. Journal of Business Research, 58(2), 126-140.

Gwinner, K. P., Gremler, D. D., \& Bitner, M. J. (1998). Relational benefits in service industries: the customer's perspective. Journal of the Academy of Marketing Science, 26(2), 101-114.

Han, S., \& Sung, H. (2008). Industrial brand value and relationship performance in business markets - A general structural equation model. Industrial Marketing Management, 37(7), 807-818.
Keh, H. T., \& Xie, Y. (2009). Corporate reputation and customer behavioral intentions: The roles of trust, identification, and commitment. Industrial Marketing Management, 38 (7), 732-742.

Kumar, V., \& George, M. (2007). Measuring and maximizing customer equity: A critical analysis. Journal of the Academy of Marketing Science, 35(2), 157-171.

Kumar, N., Scheer, L. K., \& Steenkamp, J. B. E. M. (1995). The effects of perceived interdependence on dealer attitudes. Journal of Marketing Research, 32(3), 348-356.

Lam, S. Y. Shankar, V., Erramilli, M. \& Murthy, B. (2004). Customer value, satisfaction, loyalty, and switching costs: An illustration from a business-to-business service context. Journal of the Academy of Marketing Journal, 32(3), 293-311.

LaPlaca, P. J. (2004). Special issue on customer relationship management. Industrial Marketing Management, 33(6), 463-464.

Lewin, J. E. (2009). Business customers' satisfaction: What happens when suppliers downsize? Industrial Marketing Management, 38(3), 283-299.

Little, J. D. C. (1970). Models and managers: The concept of a decision calculus. Management Science, 16(8), 466-485.

MacKenzie, S. B., Podsakoff, P. M., \& Jarvis, C. B. (2005). The problem of measurement model misspecification in behavioral and organizational research and some recommended solutions. The Journal of Applied Psychology, 90(4), 710-730.

Mantrala, M. K., Sinha, P., \& Zoltners, A. A. (1992). Impact of resource allocation rules on marketing investment-level decisions and profitability. Journal of Marketing Research, 29(2), 162-175.

Metters, R., \& Marucheck, A. (2007). Service management - Academic issues and scholarly reflections from operations management researchers. Decision Sciences, 38(2), 195-214

Morgan, M. G., \& Henrion, M. (1990). Uncertainty: A guide to dealing with uncertainty in quantitative risk and policy analysis. Cambridge, NY: Cambridge University Press.

Nijssen, E., Singh, J., Sirdeshmukh, D., \& Holzmueller, H. (2003). Investigating industry context effects in consumer-firm relationships: Preliminary results from a dispositional approach. Journal of the Academy of Marketing Science, 31(1), 46-60.

Oliver, R. L. (1999). Whence consumer loyalty? Journal of Marketing, 63(4), 33-44.

Rust, R. T., Lemon, K. N., \& Zeithaml, V. A. (2004). Return on marketing: Using customer equity to focus marketing strategy. Journal of Marketing, 68(1), 109-127.

Rust, R. T., Moorman, C., \& Dickson, P. R. (2002). Getting returns on quality: Revenue expansion, cost reduction, or both? Journal of Marketing, 66(4), 7-24.

Rust, R. T., Zahorik, A. J., \& Keiningham, T. L. (1995). Return on quality (ROQ): Making service quality financially accountable. Journal of Marketing, 59(2), 58-70.

Seggie, S. H., Cavusgil, E., \& Phelan, S. E. (2007). Measurement of return on marketing investment: A conceptual framework and the future of marketing metrics. Industrial Marketing Management, 36(6), 834-841.

Selnes, F. (1998). Antecedents and consequences of trust and satisfaction in buyerseller relationships. European Journal of Marketing, 32(3/4), 305-322.

Singh, J., \& Sirdeshmukh, D. (2000). Agency and trust mechanisms in consumer satisfaction and loyalty judgments. Journal of the Academy of Marketing Science, 28 (1), 150-167.

Sweeney, J. C., Soutar, G. N., \& Johnson, L. W. (1999). The role of perceived risk in the qualityvalue relationship: A study in a retail environment. Journal of Retailing, 75(1), 77-105.

Tenenhaus, M., Esposito Vinzi, V., Chatelin, Y. M., \& Lauro, C. (2005). PLS path modeling. Computational Statistics \& Data Analysis, 48(1), 159-205.

Venkatesan, R., \& Kumar, V. (2004). A customer lifetime value framework for customer selection and resource allocation strategy. Journal of Marketing, 68(4), 106-125.

von Winterfelt, D., \& Edwards, W. (1986). Decision analysis and behavioral research. Cambridge, NY: Cambridge University Press.

Wooldridge, J. M. (2002). Econometric analysis of cross section and panel data. Cambridge, MA: The MIT Press.

Zeithaml, V. A. (1988). Consumer perceptions of price, quality, and value: A means-end model and synthesis of evidence. Journal of Marketing, 52(3), 2-21.

Zeithaml, V. A. (2000). Service quality, profitability and the economic worth of customers: What we know and what we need to learn. Journal of the Academy of Marketing Science, 28(1), 67-85.

Zhu, Z., Sivakumar, K., \& Parasuraman, A. (2004). A mathematical model of service failure and recovery strategy. Decision Sciences, 35(3), 493-525.

Sandra Streukens is assistant professor of marketing with the Department of Marketing and Strategy at Hasselt University (Belgium). Her main research interests include services marketing, research methodology, service employee management, and return on services. Her work is published in international journals such as Marketing Letters, Journal of Economic Psychology, Journal of Business Research, Industrial Marketing Management, Information and Management, Managing Service Quality, and International Journal of Service Industry Management.

Stan van Hoesel is professor of operations research with the Department of Quantitative Economics at Maastricht University (The Netherlands). His main research interests include network design, frequency assignment, and combinatorial optimization. His work is published in international journals such as Management Science, European Journal of Operations Research, Transportation Science, International Journal of Production Economics, and Mathematical Programming.

Ko de Ruyter is professor of interactive marketing and international service research at Maastricht University (The Netherlands). His main research interests include service teams and virtual communities. His work is published in international journals such as Management Science, Journal of Marketing, Journal of the Academy of Marketing Science, Journal of Consumer Research, Journal of Retailing, and Journal of Service Research. 